\title{
Analysis of Exposure to Foreign Exchange Risk for U.S. Pharmaceutical Industry
}

\author{
Niu Shuting \\ Bangkok Business School \\ YNUFE \\ Kunming, China \\ tingnst@hotmail.com
}

\begin{abstract}
Multinational companies with a large proportion of foreign operations face one same problem which is foreign exchange risk. As for the world's largest economy, the United States has various kinds of industries that have global business and trade with currencies of different countries. American pharmaceutical industry is a very typical one, and I choose five sample firms (Merck, AbbVie, Pfizer, Bristol Myers and GSK) with comparably large size, healthy financial status and a lot of international business to analyze the exposure to foreign exchange risk and discuss the management of the risk and finally come up with my own recommendations.
\end{abstract}

Keywords-pharmaceutical industry; foreign operations; exposure to foreign exchange risk; risk management

\section{INTRODUCTION}

The global pharmaceutical industry is comprised of companies that develop, produce, and market drugs. Pharmaceutical products, once developed, are primarily distributed through wholesalers, and are then sold to pharmacies or distributed in hospitals. This industry can be segmented into two broad classes. First, the branded drug segment is comprised of companies that develop (and therefore patent), produce, and market their own branded drugs [2]. Second, the generic drug segment is comprised of companies that produce (and sometimes market) drugs at low cost, utilizing expired patents. In the analysis I focus on the former segment of branded pharmaceuticals, as all five of the companies I chose fall into this class.

The branded drug segment revolves largely around the immense expense of research and development. Large branded pharmaceutical companies often spend many years (and many billions of dollars) developing drugs in the hopes that the profits earned due to the exclusivity (patent protection) of the drug will provide a significant return in the remaining years prior to patent expiration. Thus, an important characteristic of this industry (and specifically this industry segment) is the issuance of a patent to protect a firm's potential return on the expensive development cycle of a branded drug [3]. The standard length of a patent is 20 years, and this holds in more than $90 \%$ of countries worldwide as long as the patent is also approved by the World Intellectual Property Organization (an arm of the United Nations). Additionally, a significant industry characteristic is the burgeoning elderly population in developed economies. This has led to an increased reliance on prescription drugs, and thus a larger customer base for many pharmaceutical companies. A constant challenge however, despite this increased customer base, is the battle for market share with generic drug companies that develops after the expiration of a patent for a valuable/popular prescription drug. Lastly, one additional dynamic within the global pharmaceutical industry is the dependency on medical reimbursement programs and policies, changes of which can materially impact revenue for pharmaceutical companies .

The pharmaceutical industry has maintained a sales growth rate of $7.07 \%$ over the past 12 years. The industry is a very mature industry with relatively large profit margins [5], and as the elderly population continues to expand in developed countries, and research and development strategies improve, the industry will continue to observe steady sales growth moving forward.

\section{FINANCIAL CHARACTERISTICS FOR THE Five SAMPLE FIRMS}

TABLE I. Key Fianancial Rations of the FIVE COMPANIES

\begin{tabular}{|c|c|c|c|c|c|}
\hline & AbbVie & Merck & Pfizer & $\begin{array}{c}\text { Bristol } \\
\text { Myers }\end{array}$ & GSK \\
\hline $\begin{array}{c}\text { Market Cap } \\
\text { \$ Billions) }\end{array}$ & $\$ 107.00$ & $\$ 169.17$ & $\$ 195.64$ & $\$ 97.80$ & $\$ 102.12$ \\
\hline $\begin{array}{c}\text { Revenue } \\
\text { (\$ Billions) }\end{array}$ & $\$ 18.79$ & $\$ 44.03$ & $\$ 51.58$ & $\$ 16.39$ & $\$ 43.90$ \\
\hline $\begin{array}{c}\text { Operating } \\
\text { Margin }\end{array}$ & $30.14 \%$ & $13.53 \%$ & $29.44 \%$ & $18.90 \%$ & $26.52 \%$ \\
\hline $\begin{array}{c}\text { R\&D to } \\
\text { Sales Ratio }\end{array}$ & $15.19 \%$ & $17.04 \%$ & $12.95 \%$ & $22.77 \%$ & $14.80 \%$ \\
\hline $\begin{array}{c}\text { Net Margin } \\
\text { Debt to } \\
\text { Asset Ratio }\end{array}$ & $21.97 \%$ & $10.00 \%$ & $22.12 \%$ & $15.64 \%$ & $20.51 \%$ \\
\hline $\begin{array}{c}\text { Current } \\
\text { Ratio }\end{array}$ & 2.59 & $19.44 \%$ & $20.02 \%$ & $20.68 \%$ & $29.47 \%$ \\
\hline Beta & 1.93 & 0.56 & 0.72 & 0.85 & 0.86 \\
\hline
\end{tabular}

The five companies I chose to analyze for this project are listed in Table I1 above, along with key financial characteristics of each firm. The first characteristic to note is that these firms are all very large companies, with market capitalizations ranging from $\$ 97.8$ billion to $\$ 195.64$ billion. Additionally, revenues for these firms ranged from $\$ 16.39$ billion to $\$ 51.58$ billion in 2013 . Thus, since these firms are all comparable in size it allows for a forthright analysis of 
their financial ratios. Analyzing the operating and net margin, it is clear that Merck maintains the narrowest margins of the group. However, Merck also maintains the lowest beta and least amount of leverage of the firms. AbbVie observes the highest operating margin. However, it is also the youngest firm of the group having recently spun-off of parent company Abbott Laboratories and thus is exhibiting characteristics attributable to a high-growth firm such as a relatively high leverage ratio and a high beta measure. Pfizer could easily be considered the most mature firm of the group [13], as it carries the greatest market cap, the highest revenue, the healthiest net margin, the second lowest leverage ratio, and also maintains operational efficiency at high levels which allows the firm to maintain the lowest $R \& D$ to sales ratio without hindering performance. Bristol-Myers Squibb is the smallest firm of the five I am analyzing, carrying $\$ 16.39$ billion in revenue in 2013. As a result of its relatively small size, it is not as operationally efficient as Pfizer and thus maintains the highest $R \& D$ to sales ratio of the group at $22.77 \%$. Finally, GlaxoSmithKline (GSK) also maintains healthy margins and a level of operational efficiency that allows a low R\&D to sales ratio. However, GSK has observed an acceleration in the growth of their accounts payable and have failed to observe the same growth in accounts receivables [6]. Thus, GSK has a current ratio of just 0.97. Overall, these firms are all very large and financially healthy with only minor balance sheet concerns.

\section{STRUCTURE OF FOREIGN OPERATIONS}

AbbVie Inc. is a global pharmaceutical company, recently spun-off from Abbott Laboratories. Its primary product is Humira, which is a treatment for rheumatoid arthritis. Owing to Humira, AbbVie controls more than half of the world's prescription drug market for rheumatoid arthritis. In 2013, approximately $46 \%$ of AbbVie's revenue occurred internationally. The firm's pharmaceutical products are sold in more than 170 countries worldwide, but more than half of the company's international sales occur in a mere seven countries: Germany, The Netherlands, Japan, The United Kingdom, Spain, France and Canada [1]. AbbVie's foreign operations are generally conducted via its distribution centers and public warehouses. Sales are conducted either directly with customers or through distributors, depending on the country. Internationally, some of AbbVie's products are cooperatively marketed and promoted with other companies. About $55 \%$ of the company's foreign sales are made through wholesalers, but no single international wholesaler accounts for more than $3 \%$ of the firm's sales.

Thus, AbbVie's international sales structure is broad and diversified so as to minimize the risk of losing any individual wholesale account. Much of AbbVie's research \& development, including clinical trials governed by the FDA, occurs in the United States. However, AbbVie's management discusses the potential of the emerging markets in Brazil, China, Mexico, and Russia [1]. A consideration for the company in regards to research and development is the fact that clinical trial regulations vary widely from one country to another. Thus, it is possible these differences could provide cost advantages to the firm if it chooses to conduct research and development in one of these emerging markets and proceed to market internationally with the resulting drugs.

Merck \& Co. traces its origins to Jacob Friedrich Merck, who purchased a drug store in Germany in 1668. In 1891, George Merck immigrated to the United States and set up Merck \& Co. in New York. As of December 2013, the US Merck \& Co. had approximately 76,000 employees in 120 countries with 31 factories worldwide [12]. It is one of the world's seven largest pharmaceutical companies.

Internationally, Merck sells pharmaceutical products primarily to drug wholesalers and retailers, hospitals, government agencies and managed health care providers such as health maintenance organizations, pharmacy benefit managers, and other institutions. In 2013, Merck obtained approximately $59 \%$ of annual revenues outside of the United States. The company's operations outside the U.S. are conducted primarily through subsidiaries. Worldwide sales were $\$ 44.0$ billion in 2013 , a decline of $7 \%$ compared with $\$ 47.3$ billion in 2012 [12]. This sales decline was driven primarily by lower sales of products whose patents expired in August 2012. Merck is comparable in size to both Pfizer and GlaxoSmithKline, as described in Part B of this project. Thus, it should realize the same benefits of scale that these companies do. However, the company has described its operations internationally as having been hampered by a lack of focus on research and development [8]. Thus, Merck announced in October 2013 that it would begin a multi-year global initiative to sharpen its research and development focus that should allow it to better allocate resources. Many dynamic factors impact the company's foreign operations. For instance, in Japan, the pharmaceutical industry is subject to biennial price reductions of certain drugs and vaccines [12] This is a government mandate not observed in the United States. However, Merck's international operations are primarily stable, and, like many other pharmaceutical companies, they obtain a large portion of their international operating revenue through wholesalers.

Pfizer is a global pharmaceutical company headquartered in New York City. By revenue, it is the fifth-largest pharmaceutical company in the world and the second-largest in the United States. Pfizer was founded in 1849 by two cousins: Charles Pfizer and Charles Erhart. The company was first a manufacturer of fine chemicals, but its discovery of the antibiotic Terramycin in the mid 1900's allowed the company to transform itself into a research-intensive pharmaceutical corporation [7].

Pfizer earns approximately $61 \%$ of its revenue outside of the United States, the majority of which comes from the manufacture and sale of biopharmaceuticalsin developed and emerging markets [13]. Internationally, Pfizer operates in numerous developed markets such as Japan, Canada, South Korea, Finland, New Zealand, Australia, and much of Western Europe [13]. It also operates in many emerging markets such as China, Brazil, Mexico, Russia, Turkey, and India. The firm's second largest national market, outside the United States, is Japan with nearly $10 \%$ of total revenues in 2013. As is the case with most multinational pharmaceutical corporations, Pfizer operates internationally via the sale of 
pharmaceutical products primarily to drug wholesalers and retailers, but also managed health care providers such as health maintenance organizations. The company, however, does realize a majority of its international revenues from each of its operating segments in starkly contrasting areas of the world [14]. For instance, most of the firm's Specialty Care and Oncology international operating segment revenues are obtained in Japan and South Korea. Conversely, most of the firm's Primary Care international operating segment revenues are observed in Western Europe, Australia, and Canada. Finally, the majority of the firm's Consumer Healthcare international operating segment revenues are observed in the emerging markets of Russia, Central Europe, and Eastern Europe. Pfizer's international research and development operations are focused in Europe, Canada, and China [9].

GlaxoSmithKline (GSK) is a multinational enterprise headquartered in London. It operates in three primary segments, pharmaceuticals, vaccines, and consumer healthcare. GSK has a vast distribution network, with 86 manufacturing facilities spread across the globe. GSK not only benefits from cheaper labor through its international exposure, but also realizes valuable information advantages through its research and development centers in the United States, Belgium, Spain, and China [15]. GSK focuses most of its internal efforts on research and development, leaving the final sale of products to retailers. The firm's most popular pharmaceutical products include Advair, Flovent, Augmentin, and Lovaza. In the Consumer Health segment, GSK manufactures many common household items, including the nutritional drink Boost, and the toothpaste, Sensodyne. (GSK "About Us")

GSK is committed to investing in continuing growth opportunities in important emerging markets, where sales grew by $5 \%$ in 2013 , and $11 \%$ in the fourth quarter, excluding China. Sales from its largest market, the United States, were steady in 2013, which was partly a result of patent expirations on certain drugs [16]. During 2013, GSK took steps to increase market share in the rapidly growing Indian market. The Indian pharmaceuticals and consumer health care segments announced plans to build new manufacturing capacity in India. In Japan, mandatory price cuts of 5-6\% have been imposed in alternating years, with sales of $£ 55 \mathrm{bn}$ growing by $2 \%$ in 2013 [6]. The demand for drugs in Japan remains high, however, buoyed by an aging population.

Bristol-Myers Squibb (BMS), a multinational BioPharma headquartered in New York City, is a leader in the development of drugs and vaccinations. BMS, like other biotechnology and pharmaceutical companies, focuses most of its resources on pioneering new products not only through internal $\mathrm{R} \& \mathrm{D}$, but through acquisitions of companies with products in the early and mid-stage of a drug's development. Like GSK, BMS attempts to gain an edge over its competitors through international access to valuable information through its R\&D facilities in Belgium, Bangalore, and Tokyo. BMS obtains most of its revenue from the United States, while deriving $34.8 \%$ of sales from both emerging and developed foreign markets [4].
In many regions outside the U.S., BMS operates in an environment of government-mandated, cost-containment programs, or under other regulatory bodies that exert downward pressure on pricing [17]. For example, pricing freedom is limited in the UK by the operation of a profit control plan and in Germany by a reference price system. Many European countries have continuing fiscal challenges as health care payers, including government agencies, and have reduced or are expected to continue reducing the cost of health care through actions that directly or indirectly impose additional price restrictions. Companies operating in these regions also face significant delays in market access for new products as more than two years can elapse after drug approval before new drugs are available for sale. Revenues in the rest of the world increased in 2013 due to volume growth for most of the company's key products, but were partially offset by unfavorable foreign exchange fluctuationsparticularly in Japan, and generic competition with their mature brands, including Plavix and Avapro [18].

\section{Discussion of Risk Management PRACTICES}

AbbVie's operations internationally expose it to many risks which the company is required to disclose by law. These include many risks common within the pharmaceutical industry, but also those that are specific to AbbVie. Since $46 \%$ of AbbVie's sales occur internationally, all of these risks are material to the firm's health(AbbVie 2013 Annual Report, p. 40).First, and foremost, a significant risk carried by the firm is the primary subject of this project: fluctuations in currency exchange rates. Because the company operates in more than 170 countries, this risk is significant and will be expounded on in a later section. Other major risks that AbbVie discloses include: changes in medical reimbursement policies and programs (similar to Medicaid in the U.S.), the changing policies of regulatory agencies, import or export restrictions, labor regulations, consequences of alterations of tax laws, limitations on expropriation of funds resulting from operations, economic concerns such as inflation or fluctuations in interest rates, and political instability including sovereign debt issues [1]. AbbVie manages its primary risk, foreign exchange risk, via a system of hedging foreign cash flows. AbbVie's detailed hedging practices are not disclosed by the firm, other than to state its hedging coverage ratio. AbbVie currently hedges approximately $75 \%$ of its foreign cash flows, leaving it exposed at a significant level to only one currency. This will be discussed in a later section. The company manages its remaining business risks in a proactive manner, making decisions with some foresight but also as any of the aforementioned risks are realized to become material.

Merck has established many practices to mitigate the risks it is exposed to via international operations. These risks include, but are not limited to: foreign exchange fluctuations, government-mandated regulatory requirements, import and export restrictions, diminished protection of intellectual property, and expropriation restrictions [1]. Due to its stature as a global pharmaceutical company, a significant portion of Merck's revenues are exposed to changes in foreign exchange rates. Thus, the company attempts to mitigate as much of this risk as possible via a system of revenue hedging, balance sheet risk management, and net investment hedging programs. 
As disclosed by the firm in its 2013 annual report, the objective of its revenue hedging program is to reduce the potential for long-term unfavorable changes in foreign exchange rates that would decrease the U.S. dollar value of future cash flows. Specifically, Merck hedges a portion of its forecasted sales no more than three years into the future [1]. The firm layers these hedges over time, increasing the position as the expected date of the forecasted revenue draws closer [19]. The company describes many of its strategies for hedging in its annual report. These strategies include: local currency put options, purchased collar options (writing a local call and buying a local put), forward contracts, and the use of foreign currency debt. Outside of foreign exchange risk, the company utilizes interest rate swaps to mitigate interest rate risk. Overall, Merck has fairly sophisticated risk management practices which are designed to mitigate all of the primary risks the company can control.

Pfizer is exposed to many business risks associated with its international operations. These risks include: foreign exchange fluctuations, expropriation restrictions, changes in intellectual property protections, trade regulations, and political unrest resulting in government instability [13].A significant portion of Pfizer's revenues are exposed to changes in foreign exchange rates. In fact, Pfizer's operations expose it to more than 100 currencies. The firm actively seeks to mitigate foreign exchange risk through operational means, the use of financial derivatives, and the use of foreign currency debt [10]. Through operational means, the company may match foreign currency revenues with foreign currency costs, and foreign currency assets with foreign currency liabilities. If operational means cannot satisfy the company's required level of mitigation, Pfizer may then utilize foreign currency forwards and foreign currency swaps to manage this risk. Alternatively, the company may seek to protect against a decline in net investment through the use of foreign currency debt.

Pfizer conducts an annual sensitivity analysis at year-end in which the company holds all other assumptions constant and assumes a change in one currency's rate relative to the U.S. dollar. Through this analysis, the company ensures that if the dollar were to depreciate against all other currencies by $10 \%$, the expected impact on Pfizer's financial statements would not be significant. Aside from foreign exchange risk, Pfizer observes interest rate risk because the company strives to maintain a predominantly floating-rate basis position. Pfizer mitigates interest rate risk through the use of interest rate swaps. The company generally issues debt with a fixed rate and then utilizes interest rate swaps to convert it to floating-rate debt [14]. Pfizer monitors its other aforementioned business risks, but cannot take direct action to mitigate them unless conditions change such that the risks materially impact the firm.

According to GSK's annual financial reports, GSK uses numerous financial derivative instruments to manage the risks of its operations [11]. The derivatives utilized are mainly composed of interest rate swaps and forward foreign exchange contracts. Interest rate swaps are used to hedge their positions in foreign currency denominated assets and liabilities which are required for different regional objectives.
However, not all financial risks are hedged-GSK operates under a selective hedging approach. For example, foreign currency transaction exposures generated from internal and external business are generally not hedged [20]. Additionally, GSK controls for foreign exchange risk in their operating subsidiaries' transaction exposure by matching income of local currencies with costs in local currencies whenever possible. Finally, in order to decrease overseas currency transaction exposure, GSK always tries to denominate borrowings and current assets in the currencies of their primary cash flows.

Bristol-Myers Squibb, like the other companies in my sample, is exposed to significant foreign exchange risk. BMS states that it utilizes cost effective hedges to reduce its economic exposure to foreign currency fluctuations. In particular, they attempt to mitigate their transaction exposure through selective hedging with forward contracts. Additionally, BMS uses forward contracts to hedge its exposure from holding large quantities of foreign currency denominated securities. Currently, BMS has $\$ 3.3$ billion in foreign currency forward contracts outstanding (BMS 2013 10-K). Their selective hedging policy leaves open the opportunity for large losses on certain unhedged positions. I will discuss any significant exposure, and my ensuing recommendations in the next section. It should also be noted that there are certainly advantages to a selective hedging approach, notably a reduction in hedging related expenses.

\section{RECOMMENDATIONS ON RISK MANAGEMENT}

To determine which currencies these companies are exposed to, I ran the following regression

$$
R_{i, t}=\alpha_{0}+\beta_{0} R_{m} t+\delta_{1} \Delta S^{d_{1} / f_{1}}+\delta_{2} \Delta S^{d_{2} / f_{2}}+\delta_{3} \Delta S^{d_{3} / f_{3}}+\varepsilon_{t} \text { : }
$$

Where $R_{i, t}$ is the return on company i's stock during period t.

$R_{m 1}$ is the return on the market in time t. The market used for the four U.S headquartered companies is an ETF that replicates the CRSP U.S Total Market Index. For GlaxoSmithKline, since $96.6 \%$ of their revenue is derived from sources outside of the United Kingdom, I used an ETF that replicates the performance of the FTSE Global All Cap Index (Yahoo! Finance).

$\Delta S^{d_{n} / f_{n}}$ is the change in the spot rate for firm i's nth most exposed currency.

Additionally, I used 5 years of monthly data, which, when converted to returns, amount to 59 observations from $1 / 29 / 2009-12 / 31 / 2013$. I will now go over the results of each regression and present my recommendations.

\section{Merck}

The top three most exposed currencies for Merck were the Euro, Yen, and Chinese Yuan. Revenue weights are shown in the table below. These weights, and those of the rest of this sample, were found using the methods from Section D (EDGAR). 
TABLE II. THE MAIN CURRENCY AND WEIGHT OF MERCK

\begin{tabular}{|c|c|}
\hline Currency & Weight \\
\hline EUR & $17.7 \%$ \\
\hline JPY & $9.2 \%$ \\
\hline CNY & $4.5 \%$ \\
\hline
\end{tabular}

Hence, the equation for Merck is the following:

$$
R_{t}=\alpha_{0}+\beta_{0} R_{m}+\delta_{1} \Delta S^{s / €}+\delta_{2} \Delta S^{s / z}+\delta_{3} \Delta S^{s / C N Y}+\varepsilon_{t}
$$

After running the regression, I obtained the following results, with p-values in parenthesis below their associated coefficients.

$$
\begin{array}{r}
\widehat{R_{t}=0.01+0.40 R_{m}}+0.18 \Delta S^{\$ / €}+0.45 \Delta S^{\$ / F}+1.1 \Delta S^{\$ / C N Y} \\
(0.43)(0.05)(0.57)(0.07)
\end{array}
$$

$n=59, R^{2}=0.22$

With a p-value of 0.07 , or just slightly less significant than the market returns, I believe Merck's exposure to the Yen is significant enough to warrant hedging consideration of the firm. Because Merck only hedges a portion of their operating exposure, I recommend they take additional measures to hedge their exposure to the Japanese yen.

\section{Pfizer}

Like Merck, the top three most exposed currencies for Pfizer were the Euro, Yen, and Chinese Yuan. With the following revenue weights (Pfizer, 2014).

TABLE III. THE MAIN CURRENCY AND WEIGHT OF PFIZER

\begin{tabular}{|c|c|}
\hline Currency & Weight \\
\hline EUR & $17.3 \%$ \\
\hline JPY & $9.2 \%$ \\
\hline CNY & $7.7 \%$ \\
\hline
\end{tabular}

Hence, the equation for Pfizer is the following:

$R_{t}=\alpha_{0}+\beta_{0} R_{m}+\delta_{1} \Delta S^{\$ / €}+\delta_{2} \Delta S^{\$ / F}+\delta_{3} \Delta S^{\$ / C N Y}+\varepsilon$

Here are the results:

$\widehat{R}_{t}=0.01+0.51 R_{m}+0.47 \Delta S^{\$ / €}+0.35 \Delta S^{\$ / \#}-0.85 \Delta S^{\$ / C N Y}$

$(0.12)(0.002)(0.05)(0.07)$

$n=59, R^{2}=0.43$

I see that there is a statistically significant relationship between Pfizer's stock returns and movements in the Yen (at the $10 \%$ level) and Euro (at the 5\% level). Although Pfizer states in its annual report that it devotes a significant amount of resources to mitigate sensitivity to foreign exchange fluctuations, and hedge accordingly, I recommend Pfizer take another look at their exposure to the Yen and Euro and make any necessary adjustments to their current risk management practices (Pfizer, 2014).

\section{Bristol-Myers Squibb}

For BMS, the top three most exposed currencies were the Euro, Yen, and British Pound. With the following revenue weights (Bristol-Myers Squibb, CO. Form 10-K).
TABLE IV. THE MAIN CURRENCY AND WEIGHT OF BRISTROL-MYERS AQUIBB

\begin{tabular}{|c|c|}
\hline Currency & Weight \\
\hline EUR & $12.9 \%$ \\
\hline JPY & $4.9 \%$ \\
\hline GBP & $2.3 \%$ \\
\hline
\end{tabular}

Here are the results:

$$
\begin{gathered}
\widehat{R}_{t}=0.02+0.40 R_{m}+0.60 \Delta S^{\xi / €}+0.19 \Delta S^{\$ / F}-0.87 \Delta S^{S / \epsilon} \\
(0.07)(0.08)(0.17)(0.50) \\
n=59, R^{2}=0.17 \quad
\end{gathered}
$$

Two interesting findings; first, this model has the lowest $\mathrm{R}$-squared of any model in my sample. This is probably due to the fact that the top three currency weights are the smallest of my five firms. Second, it is surprising that movements in the pound are more significant than movements in the market for explaining variation in BMS' stock returns. Hence, I recommend BMS take additional hedging measures to reduce potential negative impacts of this exposure to the British pound.

\section{AbbVie}

AbbVie began trading as a separate security on 1/2/2013. As a result, to get five years of data I used Abbott's stock returns from 1/27/09-1/1/13, and then AbbVie's from 1/2/1312/31/13.

Here are the top three currencies by weight for AbbVie (AbbVie 2013 Annual Report). Since the annual report stated that $16.7 \%$ of AbbVie's revenue came from "other" countries, I used the trade weighted dollar index (TWDI) just as with Merck from part D to determine AbbVie's net exposure to other foreign exchange fluctuations in 2013 (FRED Economic Data). Thus, for this study, in addition to the Euro and Yen, I will also test the next largest currency according to the index, the Chinese Yuan.

TABLE V. THE MAIN CURRENCY AND WEIGHT OF BRISTROL-ABBVIE

\begin{tabular}{|c|c|}
\hline Currency & Weight \\
\hline EUR & $17.3 \%$ \\
\hline TWDI & $16.7 \%$ \\
\hline JPY & $3.3 \%$ \\
\hline
\end{tabular}

Here are the results:

$$
\begin{aligned}
& \widehat{R}_{t}=0.009+0.25 R_{m}+0.55 \Delta S^{S / €}+0.21 \Delta S^{S * z}+0.75 \Delta S^{S / C N Y} \\
& n=59, R^{2}=0.23 \quad(0.27)(0.19)(0.07)(0.39)
\end{aligned}
$$

AbbVie has a statistically significant exposure to the Euro. Since they stated in their annual report that they only hedge $75 \%$ of their foreign cash flows, I recommend they take additional hedging measures against the Euro.

\section{GlaxoSmithKline}

The top three most exposed foreign currencies for GSK were the US dollar, Chinese Yuan, and the Euro (GlaxoSmithKline 2013 Annual Report). 
TABLE VI. THE MAIN CURRENCY AND WEIGHT OG GSK

\begin{tabular}{|c|c|}
\hline Currency & Weight \\
\hline USD & $32.9 \%$ \\
\hline CNY & $19.5 \%$ \\
\hline EUR & $18.9 \%$ \\
\hline
\end{tabular}

Here are the results from the regression:

$$
\begin{aligned}
& \widehat{R_{t}}=0.002+0.48 R_{m}-0.20 \Delta S^{f / s}+1.43 \Delta S^{f / C N Y}-1.1 \Delta S^{f / \epsilon} \\
& n=59, R^{2}=0.24
\end{aligned}
$$

$n=59, R^{2}=0.24$

(he returns of GSK and the world stock market portfolio. However, there is no statistically significant relationship between any of GSK's top three currencies. I therefore recommend they continue their current risk management policies.

\section{ACKNOWLEDGMENT}

I would like to express my heartfelt gratefulness to all those who helped me during the writing of this thesis. First of all I would like to thank Jake Smith, who offered me so much of the data, resources and advice that I couldn't do on my own. Also I really appreciate all the help provided by KuanYu Chen, Chi-Kai Hung, Kenneth Sechler and Yuguang Zhang, who were my graduate classmates with abundant relevant knowledge and practical experience.

I also owe a special debt of gratitude to Hao Yin, who insisted on me writing this thesis and gave me a lot of instructions. In addition, Dean Ersi Liu of International Business School and Dean Honglie Zhang of Bangkok Business School, they have inspired me a lot when choosing the direction of the thesis.

I should finally like to express my gratitude to my beloved parents who have always been helping me out of difficulties and supporting without a word of complaint.

\section{REFERENCES}

[1] AbbVie 2013 Annual Report, Retrieved from AbbVie Corporate: http://www.AbbVieinvestor.com/phoenix.zhtml?c=251551\&p=irol-sec.
[2] A. Addison, V. Lawson, Retrieved, December 15, 2014.

[3] Bristol-Myers Squibb 2013 Annual Report, Retrieved from BristolMyers Squibb Website: http://investor.bms.com/investors/financialinformation/annual-reports/default.aspx.

[4] Bristol-Myers Squibb: Our Company. (n.d.). Retrieved December 15, 2014, from: http://bms.com/ourcompany/Pages/home.aspx.

[5] GDP Data (current USD) Retrieved December 14, 2014, from WorldBank: http://data.worldbank.org/indicator/NY.GDP.MKTP.CD

[6] GlaxoSmithKline plc. Retrieved December 15, 2014, from: http://finance.yahoo.com/q?s=GSK

[7] GlaxoSmithKline 2013 Annual Report. Retrieved December 15, 2014 from GSK Investor Relations:http://www.gsk.com/media/325156/ annual-report- 2013.pdf

[8] GSK. About Us. (n.d.). Retrieved December 15, 2014, from http://www.gsk.com/en-gb/about-us/.

[9] GSK - Risk Management \& Compliance Policy PDF. Retrieved December 15, 2014, from http://risk.management6.com/GSK---RiskManagement-Compliance-Policy-pdf-e1277.html.

[10] Health expenditure, public (\% of GDP). Retrieved December 14, 2014, from http://data.worldbank.org/indicator/SH.XPD.PUBL.ZS

[11] IBIS World Industry Report. Retrieved from IBISWorld Market Research: http://clients1.ibisworld.com.ezproxy.lib.usf.edu/reports/gl/ industry/default.asp ?entid $=720$

[12] Merck, CO. Form 10-K. (2014, February 27). Retrieved December 14, 2014 from: https://www.sec.gov/Archives/edgar/data/310158/ 000031015814000009/mrk1231201310k.htm.

[13] Pfizer "About Us". Retrieved from Pfizer Corporate Website: http://www.pfizer.com/about/history/history

[14] Pfizer 2013 Annual Report. (n.d.). Retrieved from Pfizer.com: http://www.pfizer.com/files/investors/presentations/FinancialReport201 3.pdf

[15] "Trade Weighted U.S. Dollar Index: Broad," Retrieved December 14, 2014.

[16] U.S. Securities and Exchange Commission. Retrieved from EDGAR: www.sec.gov/edgar.shtml

[17] VT: Summary for Vanguard Total World Stock Inde- Yahoo! Finance. Retrieved December 14, 2014.

[18] VTI: Summary for Vanguard Total Stock Market ETF- Yahoo! Finance. Retrieved December 14, 2014.

[19] F.A.Q. Wipo, "Retrieved from World Intellectual Property Organization."

[20] Yahoo Finance, "Retrieved from Yahoo." 